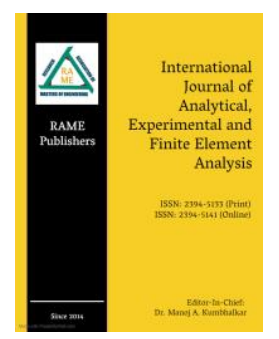

Ajju R. Justus ajurjustus@yahoo.co.in

Independent Researcher, Department of Mechanical Engineering, Kerala, India

\title{
Effect of Seating Posture and Hard Sitting on Metal Chair Frame Design
}

Abstract - The chair is essential seating furniture in virtually all our daily activities. The present study observes that the anthropometric data, seating posture, and hard sitting are all equally crucial design parameters in chair design. Studies often focus on one design criteria while neglecting the others. Insufficient design criteria for chairs have caused many premature failures resulting in human injuries and loss of resources. Relevant anthropometric data from previous studies are considered for defining the dimensions of an ergonomic metal chair frame that forms the basis for an ergonomic chair. The person's weight at the center of gravity is transferred to the chair frame using suitable rigid body elements. The displacement and stress values from the static analysis are observed. The Variation of the values from the normal seating posture, which is the commonly used position in chair frame design, is observed. Variation of displacement and stress values under four seating postures highlights the importance of posture as a design criterion to ensure the structural integrity of the chair frame. The present study also recognizes hard sitting as an essential design criterion. Hard sitting, an impact load, and an observed phenomenon in sitting, is analyzed as an equivalent static load. The analysis shows that the increase in stress under impact load is approximately 5.4 times the same load applied as a dead weight. The present study is a preliminary work in understanding the importance of seating posture and hard sitting as chair and chair frame design parameters.

Keywords - Chair frame, impact load, seating posture, hard sitting, stress analysis, design

\section{INTRODUCTION}

Chairs are the most commonly observed seating furniture that finds application in almost any place like homes, workplaces, and public places. Its primary purpose is to provide the user with a comfortable and ergonomic seating posture. It helps them carry out the desired activities like communication, studies, work, research, watching movies, and playing games for a longer duration

Research Paper - Peer Reviewed

Published online - 16 August 2021

\section{(C) 2021 RAME Publishers}

This is an open access article under the CC BY 4.0 International License https://creativecommons.org/licenses/by/4.0/

Cite this article - Ajju R. Justus, "Effect of Seating Posture and Hard Sitting on Metal Chair Frame Design", International Journal of Analytical, Experimental and Finite Element Analysis, RAME Publishers, vol. 8, issue 3, pp. 102-107, 2021.

https://doi.org/10.26706/ijaefea.3.8.20210711 without fatigue and with higher efficiency. The inability of a chair to perform its function satisfactorily signifies its failure. Failure of a chair can mean stress magnitudes beyond its design limit, resulting in fracture or excessive yielding. It often leads to human injury of varying degrees $[1,2]$. Failure of a chair can also imply its inability to provide the desired comfort level due to poor ergonomics. It causes musculoskeletal disorders [3, 4]. Anthropometry is a crucial aspect of chair design [5]. If adequately included in chair design, anthropometry can significantly improve the ergonomics and comfort level of the chair. However, most studies in the public domain concentrate on one aspect of design while neglecting the other. Anthropometric data showed Variation among races, countries, states, age, and even gender [6-9]. Anthropometric data from various sources [10-15] is 102

Int. J. of Analytical, Experimental and Finite Element Analysis 
studied and compared. Experimental analysis of body weight distribution on the chair seat components under various configurations signifies the importance of finding an optimal configuration to reduce the load distributed to the seat to help alleviate the stress on the spine [16]. Sandbag free drop tests at various heights [17] provide the necessary data to simulate hard sitting conditions. The effects of different seat foundations on the magnitude of impact forces are also observed. The finite volume method is used for understanding the displacement and stress distribution in a wooden chair skeleton [18]. Stiffness analysis of a statically indeterminate wooden chair frame based on the direct stiffness method and numerical software analysis shows a good correlation between the methods [19].

The present study highlights the importance of integrating anthropometric data in structural design for creating an ergonomic chair. The seating posture and hard sitting as essential criteria in chair and chair frame design are also considered in depth in this study through numerical analysis. This work also highlights that it might be more appropriate to model user loads as impact loads to avoid any unforeseen structural failures.

\section{ASSUMPTIONS}

1. The chair frame material is isotropic, homogeneous, and continuous.

2. The leg's contact with the ground is modeled as fixed support.

3. The person's center of gravity is in the plane of symmetry.

4. All the frame joints are ideally welded with the same base material.

5. The mass of the person sitting on the chair is $100 \mathrm{~kg}$.

\section{DeSign Methodology}

The anthropometric data of an ergonomic chair for 95 percentile of males is taken from [9]. Considering this data as a primary reference and giving suitable allowances for frame thickness and comfort, a chair frame is modeled using CATIA. The material considered for the chair frame is Al2024 alloy. It is selected based on the requirements of a chair frame. It has a high strength-to-weight ratio and relatively low density. The relevant material properties are given in Table 1. A technical drawing of the chair frame with relevant dimensions is shown in Figure 1.

TABLE I

MATERIAL PROPERTIES

\begin{tabular}{|l|c|}
\hline \multicolumn{1}{|c|}{ Name } & Value \\
\hline Material & Al2024- T351 \\
\hline Density $\left(\mathrm{kg} / \mathrm{m}^{3}\right)$ & 2770 \\
\hline Young's Modulus of Elasticity $(\mathrm{GPa})$ & 72.4 \\
\hline Poisson ratio & 0.33 \\
\hline Tensile Yield Strength $(\mathrm{MPa})$ & 325 \\
\hline
\end{tabular}
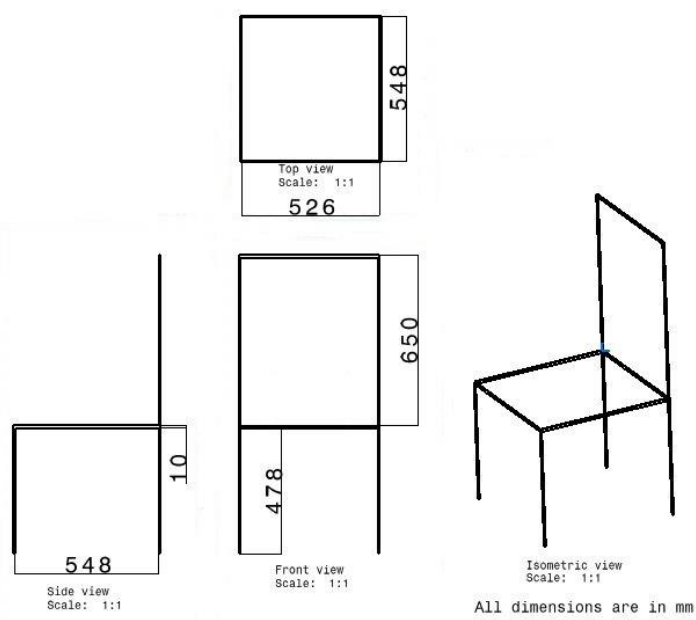

Figure 1: Chair frame dimensions

The CAD model of the chair frame is designed as a single solid component. The legs have a square crosssection of side $5 \mathrm{~mm}$. The 3D model is discretized by exporting it to Hypermesh for meshing. A convergence study is done to determine the optimal mesh size for an optimal tradeoff between accuracy and computation time. The Variation of displacement with element size is shown in Figure 2. The results of the convergence study show that an element size of 6 is optimal for the model.

The material properties and boundary conditions are added to the discretized model. The chair is assumed to be 
rigidly fixed to the ground. All the chair frame nodes in contact with the ground are constrained in all six degrees of freedom.

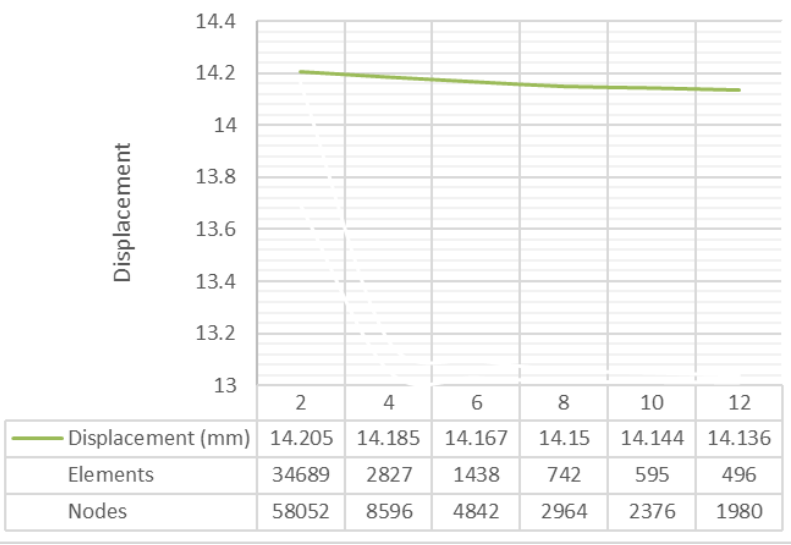

Figure 2: Convergence Study

Static analysis of the chair frame is carried out under various seating postures to evaluate the Variation of parameters like stress and displacements. An equivalent impact loading is also carried out to consider the effect of hard sitting on design to avoid unexpected failures.

\section{ANALYSIS AND RESUlts}

For the present study, four possible sitting positions are considered, as shown in Figure 3.

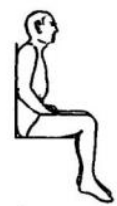

1

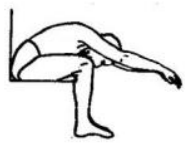

2

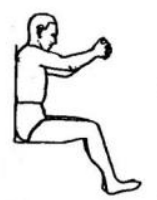

3

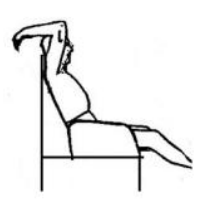

4
Figure 3: Various sitting positions considered [20]

The center of gravity of each seating posture is suitably calculated based on an earlier experimental report for a different purpose [20]. The center of gravity of different positions is shown in Figure 4. As per the stated assumption, the $\mathrm{x}$-coordinate of c.g is constant for all the positions and is in the plane of symmetry of the chair frame. Table 2 gives a brief description of the positions under consideration.

The person's weight acts through the center of gravity of the position and is distributed to the relevant parts of the chair frame through suitable rigid body elements (RBE3). The displacement and stress values for each position are found out through numerical analysis using ANSYS Mechanical APDL. It is carried out for various seating postures. Impact load effects on the chair frame are also analyzed by considering suitable equivalent static loads.

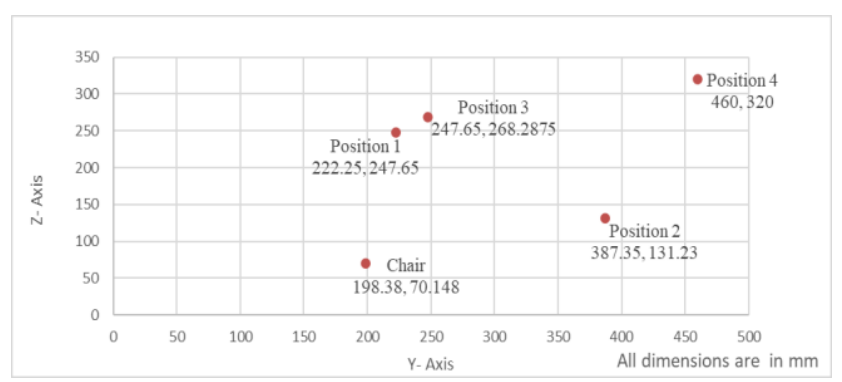

Figure 4: Center of gravity of various sitting positions.

TABLE II

POSITION NOMENCLATURE

\begin{tabular}{|c|c|}
\hline Position & Description \\
\hline Position 1 & Normal sitting, i.e., Both hands in lap. \\
\hline Position 2 & Trunk flexed on thighs; arms extended \\
& Both hands on overhead controls \\
\hline Position 3 & Inclined and holding to seatback. \\
\hline Position 4 & sitting. \\
\hline Impact Analysis & Impact load applied to position 1, i.e., Normal \\
& \\
\hline
\end{tabular}

\section{A. Effect of Sitting Posture}

Loads are applied as point loads to the center of gravity, which are distributed to the chair frame. Figure 5 shows the meshed model for Position 1 and Position 2. It may be noted that Position 2 does not have contact with the backrest, so meshing is done accordingly. The Variation of the displacement and stress values with respect to the normal sitting position is noted.
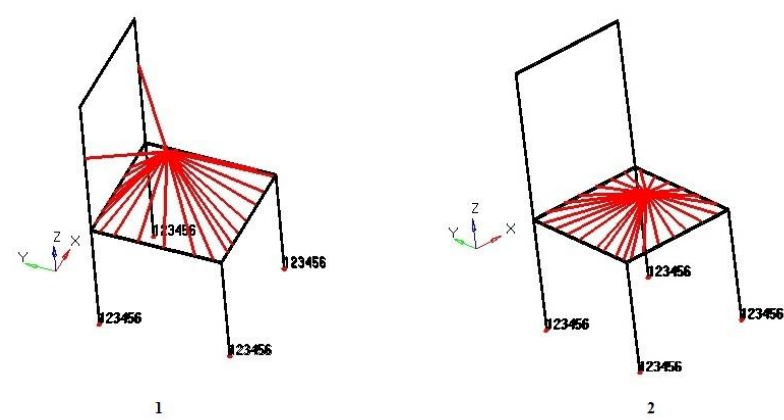

Figure 5: Meshed model for Position 1 and Position 2 
The Von mises stress values for each position are recorded, and the maximum displacement, which was in the y-direction, is tabulated in Table 2. The Von mises stress for positions $1 \& 2$ is shown in Figures $6 \& 7$, respectively.

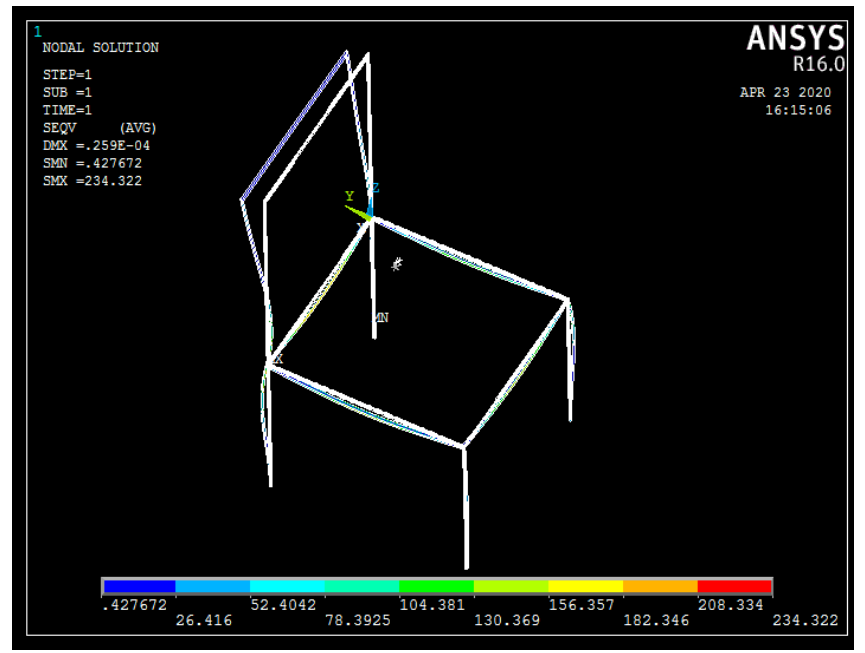

Figure 6: Von mises stress for Position 1

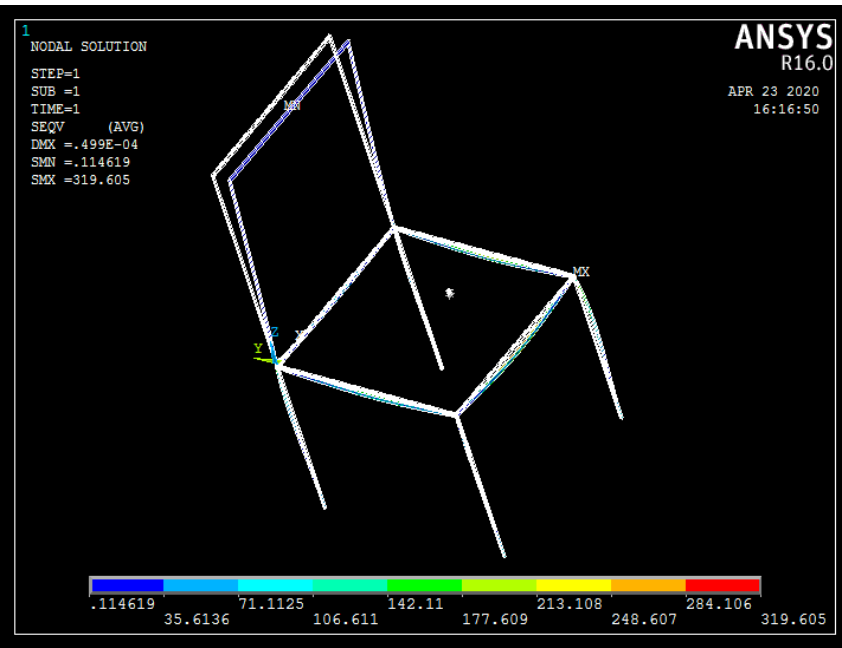

Figure 7: Von mises stress for Position 2

TABLE III

DISPLACEMENT \& STRESS VARIATION

\begin{tabular}{|c|c|c|}
\hline Position & $\begin{array}{c}\text { Von-Mises Stress } \\
(\mathrm{Pa})\end{array}$ & $\begin{array}{c}\text { Y-Direction } \\
\text { displacement }(\mathrm{m})\end{array}$ \\
\hline 1 & 234.322 & $2.42 \mathrm{E}-05$ \\
\hline 2 & 319.605 & $6.83 \mathrm{E}-06$ \\
\hline 3 & 237.546 & $6.36 \mathrm{E}-06$ \\
\hline 4 & 1252.77 & $1.00 \mathrm{E}-05$ \\
\hline Impact Analysis & 1496.22 & $1.55 \mathrm{E}-04$ \\
\hline
\end{tabular}

\section{B. Effect of Hard Sitting}

To emphasize the importance of hard sitting in chair frame design, impact force generated under hard sitting having a time interval of 0.05 seconds (21)[21] is analyzed under static conditions, and stress analysis is carried out. The Variation in displacement and stress values are recorded.

The impact analysis is carried out by finding the impact load using the following equations.

$$
\begin{gathered}
\mathrm{F} \Delta \mathrm{t}=\Delta(\mathrm{mv}) \\
\mathrm{v}=\sqrt{2 g H}
\end{gathered}
$$

$\mathrm{m}=$ mass of the person $(100 \mathrm{~kg})$

$\Delta \mathrm{t}=$ time of impact (0.05 seconds)

$\mathrm{H}=$ height of fall, which is the difference between the c.g at the standing position and normal sitting $(0.5 \mathrm{~m})$

$\mathrm{v}=$ velocity of the person before impact (calculated to be $3.132 \mathrm{~m} / \mathrm{s}$ )

$\mathrm{F}=$ Impact load (calculated to be $6264 \mathrm{~N}$ )

The stress value under impact load is $1496.22 \mathrm{~Pa}$, which is of very high magnitude compared to the stress value of $234.322 \mathrm{~Pa}$ in Normal sitting. The Von mises stress distribution under hard sitting is shown in Figure 8.

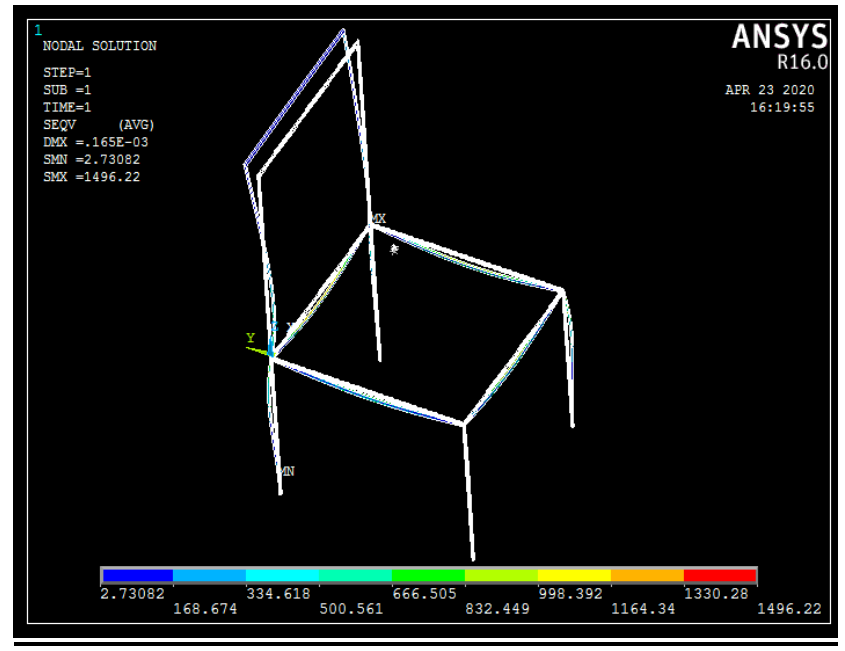

Figure 8: Von mises stress under hard sitting.

\section{DISCUSSION}

Anthropometric data varies from country to country and even region to region. Thus, chair design is complimented by localized anthropometric data. Presently, 
anthropometric data is quite random and scattered. The present study considers the available anthropometric data and selects the maximum values for the 95 percentiles for males. It is to understand the possible extreme conditions in chair design. Preliminary analysis shows that applying the person's weight either as an inertial load or as a point load at the center of gravity of the sitting position resulted in negligible variations.

The ground contact of the chair frame is modeled as fixed supports, which is appropriate for specific situations. Depending upon the scenario, various studies model ground contact as roller, hinged, fixed supports, or a combination of these. Variation in displacement and stress values may be observed on changing the constraints. The present study tries to provide an overview of the extreme conditions, and therefore fixed supports are chosen. Future studies on the effect of different constraints on chair design are recommended.

Hard sitting is a commonly observed phenomenon, particularly in the younger generation users who tend to fall on the chair rather than gradually sit, creating an impact load on the chair frame. However, this aspect is not a commonly considered parameter in chair design. The present study shows that this impact load, when analyzed as an equivalent static load, shows a rise in stress magnitude of around 5.4 times the normal sitting for the same posture. Hard sitting can be a predominant cause of chair failure and should be considered in chair design. There is scope for research on understanding the effects of hard sitting.

\section{CONCLUSIONS}

A significant variation in the displacement and stress values in the chair frame under various sitting positions is observed due to changes in the center of gravity of the position. The analysis of hard sitting on the chair frame as an impact force shows enormous Variation in the values compared to the same load under normal sitting. It can be concluded that the above factors must be considered in the design of a chair frame to avoid unforeseen or premature failure and to prevent injury to the person using the chair.
The displacement and stress values were well below the permissible limit, suggesting huge potential for material saving and design optimization. However, buckling can become a predominant mode of failure under thin dimensions, and a detailed analysis is required to understand and prevent the same. Thus, this study signifies the need for more varied and detailed design criteria to prevent premature failure of the chair frame.

\section{REFERENCES}

[1] Chen Y, Tang Y, Allen V, DeVivo MJ., "Fall-induced spinal cord injury: External causes and implications for prevention”, J Spinal Cord Med, 2016 Jan; 39(1):24-31. https://doi.org/10.1179/2045772315Y.0000000007

[2] Gordon A. Nurse, 40, wins $£ 500,000$ NHS payout after defective chair collapsed under him at work in accident that he said left him disabled for life. MailOnline [Internet]. 2019 Nov 19; Available from: https://www.dailymail.co.uk/news/article-7701535/Nurse40-wins-500-000-NHS-payout-chair-collapsed.html

[3] Sepehri S, Habibi AH, Shakerian S., "The relationship between ergonomic chair and musculoskeletal disorders in north of Khuzestan's students. Eur", J Exp Biol, 2013, volume 3(4):181-7.

[4] Musa AI, Ismaila SO, Adejuyigbe SB, Akinyemi OD, "Ergoeffects of designed school furniture and sitting positions on students' behaviour and musculo-skeletal disorder in Nigerian tertiary institutions", Manag Sci Lett, 2011; 1:3314. https://doi.org/10.5267/j.msl.2011.03.002

[5] Helander MG, Czaja SJ, Drury CG, Cary JM, Burri G., “An Ergonomic Evaluation of Office Chairs", Off Technol People, 1987 Mar 1;3(3):247-63. https://doi.org/10.1108/eb022651

[6] Saha PN, "Anthropometric characteristics among industrial workers in India", International Symposium on Ergonomics in Developing Countries, Jakarta, Indonesia; 1985. p. 15861.

[7] Dewangan KN, Kumar GVP, Suja PL, Choudhury MD., "Anthropometric dimensions of farm youth of the north eastern region of India, Int $J$ Ind Ergon, 2005 Nov;35(11):979-89. https://doi.org/10.1016/j.ergon.2005.04.003

[8] Hu H, Li Z, Yan J, Wang X, Xiao H, Duan J, et al. "Anthropometric measurement of the Chinese elderly living 
in the Beijing area", Int J Ind Ergon, 2007 Apr, volume 37(4), pp. 303-11.

https://doi.org/10.1016/j.ergon.2006.11.006

[9] Jeong BY, Park KS., "Sex differences in anthropometry for school furniture design", Ergonomics. 1990 Dec;33(12):1511-21. https://doi.org/10.1080/00140139008925350

[10] Helander M. A., "Guide to Human Factors and Ergonomics", [Internet]. Second. Boca Raton: CRC Press; 2005. 408 p. https://doi.org/10.1201/b12385

[11] Majumder J., "Anthropometric dimensions among Indian males - A principal component analysis”, Eurasian $J$ Anthropol. 2014;5(2):54-62.

[12] Ismaila SO, Musa AI, Adejuyigbe SB, Akinyemi OD, "Anthropometric design of furniture for use in tertiary institutions in abeokuta, South-Western Nigeria”, Eng Rev. 2013; volume 33(3):179-92.

[13] Taifa IW, Desai DA., "Anthropometric measurements for ergonomic design of students' furniture in India”, Eng Sci Technol Int J,. volume 20(1): 232-9. https://doi.org/10.1016/j.jestch.2016.08.004

[14] Ansari S, Khan MI., "Ergonomic design of VDT workplace for Indian software professionals", Int J Tech Res Appl. 2014; volume 2(4):62-6.

[15] Noshin L, Gupta HS, Kibria MdG., "Office chair design: a systematic approach of ergonomic design based on the anthropometric measurement of Bangladeshi people", Int $J$ Res Ind Eng., 2018; volume 7(2):224-34. https://doi.org/10.22105/RIEJ.2018.128451.1040

[16] Nag PK, Pal S, Kotadiya SM, Nag A, Gosai K., "Humanseat interface analysis of upper and lower body weight distribution”, Int J Ind Ergon. 2008; volume 38(5-6): pp. 539-45. https://doi.org/10.1016/j.ergon.2007.10.024

[17] Li M, Wu Z, Tackett B, Zhang J., "Human and test bag impact loads on stationary seating”, 2017;49(3).

[18] Horman I, Hajdarevic S, Martinovic S, Vukas N., "Numerical Analysis of Stress and Strain in a Wooden Chair”, Drv Ind. 2010;61(3):151-8.

[19] Hajdarević S, Busuladžić I., "Stiffness Analysis of Wood Chair Frame", Procedia Eng. 2015; 100:746-55. https://doi.org/10.1016/j.proeng.2015.01.428

[20] JJ S., "Determination of centers of gravity of man", [Internet]. US: Civil Aeromedical Research Institute; 1962 Aug p. 1-37. Report No.: 62(14). Available from: http://purl.access.gpo.gov/GPO/LPS71833

[21] Hu L, Tackett B, Tor O, Zhang J., "Analysis of sitting forces on stationary chairs for daily activities", Ergonomics, 2016; volume 59(4): pp. 556-67. https://doi.org/10.1080/00140139.2015.1080311 